\title{
Foreign Operation Mode Combinations and Internationalization
}

\author{
Petersen, Bent; Welch, Lawrence S.
}

Document Version

Final published version

Publication date:

1999

\section{License \\ CC BY-NC-ND}

Citation for published version (APA):

Petersen, B., \& Welch, L. S. (1999). Foreign Operation Mode Combinations and Internationalization. Department of International Economics and Management, Copenhagen Business School. Working Paper / Department of International Economics and Management, Copenhagen Business School No. 6-1999

Link to publication in CBS Research Portal

\section{General rights}

Copyright and moral rights for the publications made accessible in the public portal are retained by the authors and/or other copyright owners and it is a condition of accessing publications that users recognise and abide by the legal requirements associated with these rights.

\section{Take down policy}

If you believe that this document breaches copyright please contact us (research.lib@cbs.dk) providing details, and we will remove access to the work immediately and investigate your claim. 


\title{
Foreign Operation Mode Combinations and Internationalization
}

\author{
Bent Petersen \\ and \\ Lawrence S. Welch
}

\author{
Address for correspondence: \\ Bent Petersen \\ Copenhagen Business School \\ Department of International Economics and Management \\ Nansensgade 19 \\ DK 1366 Copenhagen K \\ Denmark \\ Tel: +4538152510 \\ Fax: +4538152500 \\ E-mail: bp.int@cbs.dk
}

Bent Petersen is Associate Professor of International Business at Copenhagen Business School, D enmark

Lawrence S. Welch is Professor of International Marketing at the Norwegian School of Management (BI) in O slo and Adjunct Professor, Department of Marketing, International Business and Asian Studies, University of Western Sydney-Nepean, Australia. 


\title{
Foreign Operation Mode Combinations and Internationalization
}

\begin{abstract}
The standard formula in theoretical and empirical studies of entry mode choice and internationalization processes of firms has been 'one foreign country, one operation mode', i.e. a singular mode approach. However, even with fairly broad operation mode definitions it is by no means exceptional to see firms having more than one operation mode in a foreign country. This paper explores the phenomenon of 'multiple', 'mixed', or 'combined' foreign operation modes. Although several occurrences of mode combinations are reported in the IB literature, the phenomenon has not yet been made the subject of direct analysis. The paper introduces a classification of multiple mode appearances based on the degree of interaction between operation modes (which vary considerably). Special attention is paid to 'mode packages', i.e. the concerted use of several operation modes in an integrated, complementary way. In a study of Danish MNCs with simultaneous use of subsidiaries and independent local intermediaries it was found that in most cases the two modes are operating in a complementary way. A framework for analyzing the roles within packages is presented and it is argued that the use of 'mode packages' may offer the multinational firm scope for improved international market penetration capacity.
\end{abstract}

\section{Key words}

Internationalization, foreign operation modes, mode combination, mode packages. 


\section{Foreign Operation Mode Combinations and Internalization}

\section{Introduction}

There has been a growing body of international business literature on the foreign market operation methods which companies use in their international activities. Much of the focus of the research has been on the entry mode decision or on subsequent mode changes, although there has been also a continuing interest in the internationalization patterns or international establishment chains over time of companies, with the operation mode as a key indicator (Agarwal and Ramaswami, 1992; Buckley and G hauri, 1998; Calof, 1993; Hill, Hwang and Kim, 1990). The stress on foreign operation mode is understandable; given its importance as a key base from which a company's ability to penetrate a foreign market springs. It is also an overt signpost of a company's commitment to a foreign market, both within and outside the company. From an empirical research perspective, it is likewise one of the most concrete forms of a company's international activity that can be readily identified and for which records often exist. Thus, much of the theorizing around internationalization and psychic distance have been based on recorded patterns of international operation mode development for the companies concerned (Johanson and Wiedersheim-Paul, 1975; Johanson and Vahlne, 1977 and 1990; Clark, Pugh and Mallory, 1997). However, in both entry mode choice and internationalization studies, and in associated conceptual development, 'foreign operation mode' has tended to be treated as a singular entity. This is despite the fact that companies often use foreign operation modes in combination (in packaged form) as a way of more effectively servicing foreign markets (Benito and Welch, 1994).

Clearly, there is a need for an examination of the subject of mode combinations in greater depth, to consider, at the least, the implications for the way in which foreign operation mode issues are approached, both empirically and conceptually. For example, do mode additions change the character of the internationalization process, facilitating the movement from a lower commitment to a higher commitment mode (or mode package)? O nce mode combinations rather than singular modes are accepted as part of 
the reality of international business operations, they raise a host of similar questions about the nature of mode choice and change over time.

In this article, therefore, we examine the issue of foreign operation mode combinations and their implications for conceptualizations and empirical investigations of international mode decision making and development over time. On the basis of a literature review we also seek to build a conceptual framework for analyzing the nature of mode combinations and the effect that they may have on companies' internationalization. As part of the process of exploration and concept development, the findings of a study of Danish companies' international operations are drawn upon. In addition, the managerial implications of the reality of mode combinations are analyzed. While there is evidence that companies are reluctant sometimes to even consider a wider range of mode options (Calof, 1993; Larimo, 1987), having developed experience and competence in using one or a limited number of modes, broadened mode combinations may offer scope for improved international market penetration capacity.

\section{Literature Review}

Although somewhat scattered, some limited evidence on the multiple mode phenomenon can be found in three different streams of International Business (IB) literature on international operation modes. O ne stream of literature concerns entry mode choice, with a focus on firms' choice between various alternative entry modes; for example, export, licensing, and production subsidiaries as alternative ways of organizing the international operations. Or, a binary choice between two major export modes may be examined: for example, foreign intermediaries versus sales subsidiaries. A second stream of literature is characterized by its focus on one particular international operation mode, such as management contracts. Here, the emphasis is on the characteristics, patterns, and reasons for using a particular mode, in the process of which combinations with alternative modes may emerge. The third stream is that of studies of internationalization patterns wherein the sequence of operation modes is observed for individual firms in one or more foreign countries since the initial entry. Studies of internationalization patterns typically are undertaken via longitudinal or retrospective research. In the following we will examine the three literature streams in terms of their reporting of multiple mode occurrences. 


\section{Entry Mode Choice Studies}

Somewhat paradoxically, the multiple mode phenomena passes almost unmentioned in entry mode literature. Traditionally, entry mode researchers have seen the entry mode choice as a choice between mutually exclusive operation modes: in its most simple version a make-or-buy choice. The main challenge has been to explain under what circumstances companies choose one mode rather than another. As an example, when does a company choose a production subsidiary instead of a licensing arrangement as the preferred mode of operation in a foreign market? In fact, observations of multiple modes might effectively have been ruled out of consideration by the framing of questions in the empirical investigation, or because responding managers have reported only what they perceive to be the main or primary mode within a broader package. Also, it is conceivable that researchers may have deleted observations of multiple modes as anomalies not included in the defined population. An exception to the general rule of multiple mode neglect is the export entry mode study by Valla (1986). Valla examined a sample of 45 French exporting manufacturers and their 165 export marketing organizations in four European countries (Italy, UK, West Germany and Sweden). Valla found that the French firms used five different singular export modes: (1) export via home-based sales force, (2) export via sales branch, (3) export via local sales agent, (4) export through an export group subsidiary, and (5) export via own sales subsidiary. Together, these singular export modes composed 120 cases. However, the balance of the sample constituted 45 cases (27 \%) of 'mixed approaches', i.e. combinations of (1) - (5). Valla (p. 45) explained the 'important finding' of a multiple mode phenomenon as 'mode addition' behaviour by the French firms.

\section{Studies on Specific Operation Modes}

In a number of studies of specific foreign operation modes the multiple mode phenomenon emerges quite strongly. For example, Brooke's (1985) research on management contract use in international operations has indicated that they are mainly utilized as part of broader foreign market servicing strategies (see also Sharma, 1983; and Welch and Pacifico, 1990). Likewise, it has been shown that foreign licensing is employed often in association with joint ventures and other forms of foreign direct investment (Contractor, 1981; Luostarinen and Welch, 1990). Franchising operations in foreign markets also are typically carried out through other modes such as joint ventures, wholly 
owned subsidiaries or master licensing arrangements (Welch, 1990). Recent research on international franchising by Danish clothing companies indicated just how much the move into franchising depended on preceding and continuing non-franchising activities and operations, including foreign direct investment, initially upstream in areas such as subcontracting and wholesaling, and later in downstream retailing (Petersen and Welch, 1999).

It is somewhat surprising that the clear indication of multiple modes in such studies has not been picked up to any extent in the other streams of literature.

\section{Internationalization Pattern Studies}

Companies frequently use variation in mode combinations as a way of dealing with the differing demands of foreign markets. Mode combinations may be used as a company's foreign market entry platform, or they might evolve through time, within and across different markets, but we know little about these aspects from existing research. To our knowledge, only two survey studies of operation mode sequences (or 'establishment chains') have reported occurrences of mode combinations. O ne of the two studies is a 'hybrid' of an entry mode choice study and an establishment chain study. In their survey of US multinationals in Scotland, Young and Hood (1976) examined the operation mode preceding 88 production subsidiaries as of 1973. Twelve (13\%) of the manufacturing affiliates had no previous market involvement. Other 66 (76 \%) manufacturing subsidiaries were preceded by three different operation modes: (1) export direct from parent or other affiliate, i.e. through a foreign-based sales force, (2) export via local sales agency, or (3) licensing arrangement. A residual 10 cases (11\%) were combinations of the three operation modes. In 8 instances the combination was (1) + (2). Clark, Pugh and Mallory (1997) carried out a more comprehensive establishment chain study of 25 UKbased firms. The survey revealed that so-called 'mixed mode' shifts - i.e. a mode (or modes) added to an existing mode - were not insubstantial, amounting to $18 \%$ (36 instances) of total mode changes (203 instances). Nine different mode combinations were observed. These involved combinations of five different operation modes: (1) exporting, (2) licensing, (3) joint venture, (4) sales subsidiary, and (5) manufacturing facilities. The most prevalent mode combination was that of licensing and a joint venture (10 instances). 


\section{Classifying Multiple Modes}

The extent of the multiple mode phenomena is closely related to how 'mode' is defined particularly its breadth: a fine-grained categorization of foreign operation modes leaves more room for observation of multiple modes than very broad categories. The entry mode literature indicates a wide span in terms of number of mode categories. To illustrate, contrast the number of categories in the IB-textbooks of Hill (1997) and Luostarinen and Welch (1990) which outline six versus twenty different foreign operation modes. The high number of foreign operation modes in the latter book results from the two authors' extended classification of various types of foreign subsidiaries according to the operations undertaken by the foreign unit.

There are many ways in which a company may combine operation modes in the attempt to enter, or develop activities in, a given foreign market. However, the fact that a company is using more than one mode in a foreign market does not necessarily denote use in an integrated package. A firm's use of multiple modes in one country may range from unrelated activities to a closely co-ordinated total business package. More specifically, we can identify four different forms of multiple modes: (1) unrelated, (2) segmented, (3) complementary, and (4) competing (see Figure 1). The four types of multiple modes can be described as follows:

\section{Unrelated Modes}

The multiple mode phenomena may reflect the operations of an entrant firm that conducts business acooss industries Thus, the operations of large, diversified multinational concerns in a foreign country are likely to be handled by different parts (divisions, strategic business units, etc.) of the organization. The Norwegian multinational Norsk Hydro in India is an example of this, as five of its product divisions, using different market servicing modes, operate in a relatively independent way (Tomassen et al, 1998). Of course, having divisions or SBUs as the unit of analysis, instead of the company as a whole, will eliminate observations of multiple local business entities that operate in different industries producing and marketing goods and services of their own.

\section{--- Figure 1 about here ---}




\section{Segmented Modes}

An entrant firm may use multiple modes that operate in the same industry, but serve different suments. Thus, the entrant firm might deem it advantageous to approach the foreign country as a collection of segments that should be tackled differently - also in terms of operation modes. Valla (1986:33) suggests segmentation as one explanation of the multiple modes observed in his study of mode choices by French exporters: 'In some cases, [the incidence of multiple modes] means that separate segments of the customer portfolio are handled differently. For instance, the largest customers may be handled directly, while others are handled through distributors or sales subsidiaries'.

Other segmentation criteria than size of customers may include: geographical regions, households versus business organizations, and infrequent buyers versus repeat buyers. An example of the latter would be a multinational fast-food restaurant chain's use of company-owned outlets at locations where customers tend to be infrequent buyers (e.g. outlets close to freeways), and franchised outlets where the customers are mainly frequent buyers (Brickley and Dark, 1987). More obvious is segmentation on the basis of geography. Large countries (both in terms of area and population), like the USA and the People's Republic of China, do not lend themselves easily to servicing by a single business unit. Two or more units are often needed to cover separate geographical regions within the country, and these units may or may not use identical operation modes. In the latter case a multiple mode phenomenon is observed at the country level. Although they are related through the shared product concept, in principle the foreign operations relating to different segments can exist independently of each other. A production subsidiary in North Carolina may operate independently of a licensee in Oregon producing for, and marketing to, the east and west of the USA respectively. Even for small companies it may be necessary to use more than one operation mode in a large foreign market such as the USA in order to achieve effective nation-wide penetration. In effect, the fact that more than one mode is being used in a foreign market could be an indicator of the type of market breakdown employed by the entrant firm.

\section{Complementary Modes}

Valla (1986) gives two explanations of the multiple mode phenomena observed in his study. The first explanation is that of segmentation mentioned above. In other cases, 
however, 'the objective of such combined approaches is clearly to increase efficiency, withaut being based on any speific segmentation. An example is a company-employed person based permanently in the country in order to back up an agent or to complemet the marketing action of a subsidiary' (Valla 1986:33, italics added). Here, the multiple modes concern the same segment or target group, but are concerned with different adivities in the value chain. As an example, a multinational corporation (MNC) may hand over the manufacturing in a foreign country to a licensee, but operate the sales and marketing through its own sales subsidiary. In this example, a clear division of labour exists between the two operation modes: the two broad business functions, manufacturing and selling, are in the hands of different entities. The separation of the manufacturing and marketing sides of foreign operations is perhaps seen most strongly in the global activities of sports shoe and clothing companies such as Nike and Reebok (Luostarinen and Welch, 1990).

However, the division of labour might be subtle. A sales subsidiary and local franchisees could both be subordinated to the same principal (for example, a multinational franchiser), catering to the same customer segment, but the franchisees operate the retail sale activities, whereas the sales subsidiary takes care of the wholesale activities including logistics. This kind of vertical division of responsibilities was found among Danish clothing companies (Petersen and Welch, 1999). Lotus Development's servicing of the European market lends evidence of a similar vertical division of tasks between subsidiaries and independent dealers. Whereas the European subsidiaries of Lotus Development in the beginning of the 1990s undertook local market research, customization of the base spreadsheet program, training of the dealers' sales staff, advertising and dealer support, the dealers themselves provided retail sales, product demonstration, user training and support (Williamson, 1992). In addition to vertical division of tasks Williamson also brings attention to a hoizontal division of responsibilities as practised by international pharmaceutical firms. 'Both drug companies and their distributors interact directly with prescribing physicians, but the manufacturers handle the flow of information while distributors take care of the flow of product, including stock rotation and inventory control.' (Williamson, 1992:65). Even within seemingly the same activity a division of labour might prevail. Take as an example a home-based, large-scale production plant and a foreign-based, small-scale production subsidiary, both plants producing the same product line. Some processes in this line, however, are more sensitive to scale economies and therefore are maintained in the 
domestic plant. O ther processes can be run cost-effectively at a low scale and are labourintensive. D ue to the availability of cheap labour and in order to minimize value-added tariff payments these processes are run by the local production subsidiary. Thus, in this case the entrant firm exports and produces abroad simultaneously in relation to the same line of product and the same foreign country. The two operation modes, the exporting and the production subsidiary complement each other in a very integrated way. Almost by definition, any assembly plant operation in a foreign country will involve export to that country (Cavusgil, Yaprak and Yeoh, 1993), but sourcing from the country-of-origin is of a common occurrence among 'fully-fledged' production subsidiaries as well (Moxon, 1982). As an example, component sourcing from the parent has been shown to be a quite frequently used strategy among European and Japanese manufacturing subsidiaries in the People's Republic of China (Schroath, Hu and Chen, 1993).

In all these cases, however, the division of labour requires a considerable degree of co-ordination between the foreign operation modes. The operation modes cannot operate independently of each other: they operate in a complementary way. As such, one may see the multiple modes as a package that cannot be unbundled. Our focus in this article is on this form of multiple modes: the concept of a mode combination, with modes working together in an integrated, cohesive manner in order to achieve certain foreign market objectives.

\section{Competing Modes}

In this form of multiple modes, the foreign country business units target the same customer group(s) and perform the same business activities, but the onnership (in-house vis-à-vis outsourcing) and location (home country visà-ìs host country location) differ. The concept of 'dual distribution' found in the (national) marketing literature (Dutta et al, 1995) may apply also to the choice of international distribution channels. 'Dual distribution' enables the manufacturer to exercise better control over the representatives. By keeping house accounts (via own sales people) in the representative's sales district the manufacturer can monitor the effort and capabilities of the independent representative. The two modes (direct sales and sales via reps) are directing the same activities towards the same segment, and thereby are involved in head-on competition. Competing modes may also occur in the situation where the entrant firm attempts a hostile take-over of an export market. The existing, local independent (but not exclusive) distributor might be 
able to resist giving up the market (the contractual obligations are still in effect) and the exporter nevertheless establishes a wholly owned, local sales organization.

There are occasions, of course, when these four distinctions will become somewhat blurred, because of changes in the foreign market and in company strategy and organization; for example, when separate distribution operations in a market are coordinated under a new subsidiary establishment, creating a more integrated package form. The degree of integration or co-ordination of multiple modes within the complementary category also may exhibit considerable variation across different foreign markets even for individual firms. Although unrelated and segmented multiple modes do not act in direct support of each other, there are many ways in which indirect support might be provided in a more general form as a result of having additional operations in the same market. For example, through staff training, staff transfers, sharing of some overheads, transfers of market information and contacts, and the like.

Thus, Figure 1 attempts to illustrate the fact that mode use is a dynamic process and may be subject to transition through alterations such as mode additions or subtractions through a period of time changing the existence and form of mode packages. The changed combinations will often occur in ways that are not reflected in studies of singular mode establishment chains (Buckley and G hauri, 1998). Some mode packages could be deliberately temporary in nature as companies seek to better position themselves for a move to a preferred form of operations in the foreign market.

An important question arising out of the consideration of mode packages or combinations is: What does mode change mean when moving from one step in the establishment chain of a company to another? Does it mean that all modes in one package are dropped in moving to a new package, or just some or only one? The extent of real change is also related to the diversity and depth of roles performed by the different modes in moving from one combination to another. There could also be shifts in the different roles within a package and of the relative weight given to the use of various modes through time. So, the continued existence of a given mode within a package at two points in time may tell us little about its function and how it was contributing to the overall internationalization of the company. Mode development may well be blurred through time for individual companies, rather than the clear, distinct individual mode patterns, viewed from the perspective of outside observers, which have been the base for arguments about the nature and process of internationalization. 


\section{Empirical Evidence}

The IB-literature offers only fragmented evidence about the extent of multiple mode use, and even less about the forms of multiple mode appearances. The few surveys that report occurrences of multiple modes (Young and Hood, 1976; Valla, 1986; Clark, Pugh and Mallory, 1997) lack details about the specific roles of the various modes in combined form. What we have are basically guesses and assumptions. A survey on the internationalization of D anish companies does, however, shed some light on which of the four multiple modes types was used.

--- Table 1 about here ---

The data on Danish companies' foreign establishments were gathered through a mail survey comprising all Danish companies that operated foreign subsidiaries. The companies were identified by studying the annual reports of all Danish companies reporting a 1994-turnover of more than DKK 40 million (equivalents to approximately US $\$ 6$ million). The population comprised 610 companies operating foreign subsidiaries. After having carried out two timely separated test interviews, questionnaires were mailed personally to the CEOs of the companies concerned. CEOs or other top executives completed most questionnaires. A reminder was mailed two months after the initial mailing. After this follow-up procedure, the number of replies reached 212, corresponding to a $35 \%$ response rate. For various reasons (e.g. limited foreign operations) a number of returned questionnaires were inadequate. After exclusion of incomplete questionnaires a total of 165 replies (27\% response rate) were usable. The study's unit of analysis was the most recent establishment (i.e. sales or production subsidiary) of Danish MNCs (Petersen and Pedersen, 1997; Pedersen and Petersen, 1998).

Of the 165 foreign subsidiaries where the mail survey enabled a track record of establishments back to the first entry in a particular market to be made, 96 foreign subsidiaries were found preceded by a local intermediary (i.e. a sales agent or a distributor). In 26 cases (27\% of the 96 subsidiaries) companies reported that cooperation with the intermediary took place subsequent to the establishment of the subsidiary. So, in these 26 cases the establishment of the subsidiary meant a change from a singular to a multiple mode arrangement. As can be seen from Table 1, the co-operation with the local intermediary took various forms. In most of the cases where it was possible 
to determine the intermediary's function, the multiple mode arrangement was either of the segmented or complementary mode form. While the above study provides limited evidence only of one area where multiple modes may exist, it is perhaps in an unexpected form - that is, continuing to use an intermediary even after a company has established its own subsidiary in the foreign market. In internationalization studies the move from agent to sales or production subsidiary appears as a discrete step. Clearly it is not possible to generalize from such a limited sample, but in line with the other traces of evidence it is indicative of a phenomenon which could well be far more widespread than is obvious from previous studies.

\section{The Use of Mode Packages}

It is evident from the discussion so far that mode combinations may appear in a variety of forms in foreign market operations. In this section we explore the roles played by mode combinations in achieving foreign involvement outcomes, as part of an attempt to extend the conceptualization of foreign operation mode combinations and their impact on the internationalization of companies. The roles may be quite diverse in the attempt to achieve such goals as foreign market penetration and profit growth. The point about mode combinations is that the various modes in a package can be used in different ways in order to achieve multiple objectives, perhaps enhancing the impact of a single mode, or indeed achieving broader outcomes than those obtainable through a single mode. The mere existence of multiple modes in an integrated package does not of itself indicate what roles they are performing, both separately and in a joint or inter-linked sense. In addition there may be substantial variation in the role played by individual modes within mode packages across markets and over time. For example, licensing might be the primary market penetration mode although leading to some associated export sales, or it could be used in a supportive role to a foreign joint venture, creating additional income and facilitating control (Welch, 1985).

\section{--- Figure 2 about here ---}

This is illustrated in Figure 2, which indicates that a combination of modes might be employed in penetrating any foreign market. Furthermore, each mode could be used in 
a variety of different roles - ranging from negligible to major use in seeking to achieve a range of potential foreign market involvement objectives. The objectives shown in Figure 2 are by no means the full limit of possibilities, merely indicative, although naturally market penetration, revenue generation and control tend to be important considerations for all companies. While a company might stress a particular mode as the primary means of entering or developing a particular foreign market - what we have labelled the primary mode in Figure 2 - other modes can be used with it in a supportive way. Perhaps in this way the other mode(s) is able to strengthen overall market penetration and revenue generation, or even perform a major role in another aspect such as technology transfer or building a positive political profile (e.g. through a licensing or technical assistance agreement). Thus, a company might emphasize a particular mode within a package as the primary mode, because it is the main mode chosen to ensure, for example, foreign market penetration and revenue generation. But there may well be some variation in primacy of role with respect to the attainment of other objectives, such as technology transfer or political leverage, even though these are viewed operating in a supportive way to the overall perceived primary mode.

This is illustrated in Figure 3, which shows a situation where the primary mode used in penetrating a foreign market for a given company is a joint venture. Primacy, in this sense, from the company's perspective, refers to the pre-eminent role of the joint venture in achieving market penetration and generating acceptable returns from the foreign operation. In association with the joint venture licensing and exporting are also employed, assisting in the achievement of revenue, control, and plant utilization objectives. In particular, licensing plays a primary role in ensuring control over the way the entrant firm's technology is used and that it is not disseminated elsewhere by the joint venture partner.

--- Figure 3 about here ---

A switch in roles for a given mode within a combination might amount to the equivalent of an overall mode change. An example could be when a company decides to change from exporting to licensing as the primary market penetration vehicle within an existing mode package, reversing their previous position. The company may have been using the foreign licensee to assemble exported parts and distribute the final product. 
Sometimes a company is unprepared to invest in its own production facility within the foreign market even though the licensing arrangement has resulted in inadequate servicing of customers. In this situation the company might see the alternative as being to more fully involve the licensee in production and service provision, along with a reduced exporting role for itself. In this situation, the outer shell of the package remains unchanged, but there is a significant change in mode roles, what could be deemed the equivalent of mode change.

Another example of change in mode role reported in the literature is when a foreign sales subsidiary, which has been established to undertake marketing activity in the foreign market, is called upon to assist in purchasing. Research indicates that, for US companies, their own foreign subsidiaries are the most frequently used resource when foreign sources of supply are being sought (Giunipero and Monczka, 1990; Monczka and Trent, 1991). Although a number of instances were found in a Finnish study of resort to foreign based sales subsidiaries for assistance with foreign purchasing it was not a common occurrence (Korhonen, 1999). Ultimately, such a change in role could be a contributor to the ability to expand into production.

The limited exploration of the use of modes within packages in this section provides an indication of the potential diversity of roles in the process of achieving multiple objectives. So-called associate modes may play an important part in achieving particular outcomes that are of concern to the entrant firm, in addition to, or in support of those sought through the primary mode. However, the primary mode has tended to be the main or only focus of research interest in entry mode and internationalization studies.

\section{Conclusion}

In this article we have sought to develop the concept of mode combinations as an important step in the extension of research into the internationalization of companies. It is perhaps surprising that the way in which foreign operation mode and mode change have been depicted in the extant IB literature has been relatively crude, and bears little resemblance to the sophisticated explanations of the internationalization process that scholars have been seeking and presenting recently, including such aspects as tacit knowledge, inter-firm and inter-person networks, inward-outward international connections, mode switching costs and de-internationalization (Athanassiou and Nigh, 
1999; Benito and Welch, 1997; Benito, Petersen and Pedersen, 1999; Björkman and Forsgren, 1997; Welch and Luostarinen, 1993). A somewhat obvious conclusion, in view of the significance of mode combinations for understanding how companies develop internationally, is the need for greater mode nuance as a basic step in the extension of research on internationalization. The mode nuance should encompass mode additions and subtractions, as well as packages from the outset, both in theoretical and empirical terms.

As a contribution to conceptualization of the subject of mode combinations we differentiated between various forms of use of multiple modes by a company in the same foreign market, not all of which could be regarded as modes in combination or in support of each other - defined as complementary modes. From a theoretical perspective, complementary modes are particularly difficult forms of multiple modes to encompass within existing simplified approaches to mode choice (see, for example, Hill, Hwang and Kim, 1990), because of potentially divergent contributions and objectives, as well as interactive effects, within an overall package. The issue of how to treat multiple modes of whatever form tends to be accentuated for large companies in situations where they have a number of operating units within a given foreign market. Even if different operating units operate in a relatively independent way within a foreign market, with different modes, there might nevertheless be less obvious formal and informal means, at headquarters and in the foreign market, whereby operations are connected, and information and other transfers take place.

The diversity of mode combinations used by internationalizing companies is evident from scattered research, including that reported in this paper from a study of Danish companies. But in some respects the scattered traces serve to emphasize that this issue needs to be approached in a more explicit way, that is, specifically requesting companies to indicate their full mode picture rather than just the perceived mainstream penetration mode. Research has shown clearly that modes in packages may play a different role in internationalization from that which applies when used on a singular basis (Welch, 1985), and this role may change through time as experience evolves and external circumstances change. High risk in the choice of an individual mode may be modified by adding other modes in an integrated package form - for example, a joint venture on its own versus one in combination with a licensing and management contract arrangement. Likewise, there are different control implications in these two situations. 
Depending on how mode combinations are deployed, and the various roles for different parts of a given package, diverse rates and forms of internationalization might well develop even within the same company. The use of management contracts, for example, inevitably requires the development and deployment of people within the organization capable of fulfilling a management role in foreign locations and being prepared to undertake expatriate assignments of varying duration. As an illustration, management contracts have been employed in the wake of turnkey projects not only to fulfil a particular market penetration purpose but also to develop company internationalization competence on a broader basis (Sharma, 1983; Luostarinen and Welch, 1990). In general, consideration of the widespread use and impact of foreign operation modes in combination points to a more intricate connection between a company's foreign operation mode development and its overall internationalization than is evident from past establishment chain studies with their focus on singular modes.

The research reported in this article is exploratory and suggestive of the type of use of mode combinations by companies in international market penetration. Clearly though, there is need for an expanded research program to provide a more comprehensive indication of the extent of use of mode combinations, and, perhaps more importantly, of the way, and for what purpose, they are used. A discussion of mode combinations, roles and objectives led to a tentative conceptual framework for analyzing the issue, but this needs to be studied in some depth at the empirical level. Undoubtedly there is a limit on

how far this process can go, because of company concerns about confidentiality, and the lack of historical data on other than the most basic mode changes. Another constraining factor is the inevitable mass and complexity of data that would be generated for even a small group of companies with well-developed international operations taken over a number of decades. It is unlikely that more comprehensive studies of mode development will easily be undertaken via broad surveys, particularly those which ask companies to reach back into the past, so that there may need to be greater resort to not just case studies but also in-process investigations.

\section{Managerial Implications}

The concept of mode combinations is an important issue in internationalization, not only from an empirical and theoretical research perspective but also has important implications for the way companies approach their international operations. The analysis of mode 
combinations is a reminder of the wide range of foreign market servicing options available to companies that make possible creative packaging in order to achieve optimal foreign market penetration outcomes. So far, the international business literature has provided little guidance regarding the nature and use of mode combinations. As noted above, research indicates that companies tend not to explore this wide range of options in operation mode decision making (Calof, 1993 and Larimo, 1987), whereas this article notes many cases where added revenue, foreign market penetration and other benefits can be achieved through more appropriate mode packaging. The analysis demonstrated that adding a mode to an existing operation, or changing the roles of modes within an unchanged overall package, may be a more effective way of responding to a change in market circumstances than undergoing the disruption and dislocation of a complete mode switch. In a general sense too, it may well provide a better basis for extracting and transferring the learning benefits from the preceding arrangement, including an assessment of those staff who need to be retained because of key knowledge, skills and networks for continuing and expanded activities. Another side to the mode concentration exhibited by many companies in international development is, of course, the risk of becoming locked-in to the use of a particular mode. The operation mode may have been used by 'chance' but then becomes the mode that thereby is best understood relative to other options; or the alternative: one bad experience therefore means that other modes are locked out. But more important is the fact that this approach prevents the company from using a combination of modes in creative ways to produce wider and deeper array of foreign market penetration options.

In general, therefore, a major task for the internationalizing company may be to change both the awareness and knowledge of other operation forms before they can be packaged in ways that strengthen the process of foreign market penetration. This may require an increased emphasis on training programs regarding international operation modes. 


\section{References}

Agarwal, S. and S.N. Ramaswami (1992): 'Choice of foreign Market entry mode: Impact of ownership, location and internationalization factors', Jaumal of Intemational Business Studies(First Q uarter), Vol. 23, pp. 1-27.

Athanassiou, N. and D. Nigh (1999): 'The Impact of U.S. Company Internationalization on Top Management Team Advice Networks: A Tacit Knowledge Perspective', StrategicManagementJaumal, Vol. 20, No. 1, pp. 83-92.

Benito, G.R.G., T. Pedersen and B. Petersen (1999): 'Foreign operation methods and switching costs: conceptual issues and possible effects,' Scandinavian Jaumal of Management, Vol. 15, pp. 213-229.

Benito, G.R.G . and L. Welch (1994): 'Foreign Market Servicing: Beyond Choice of Entry Mode', Jaumal of Intemational Markeing Vol. 2, No. 2, pp.7-27.

Benito, G.R.G. and L. Welch (1997): 'D e-internationalization,' Management Intemational ReviewVol. 37, Special Issue No. 2, pp. 7-25.

Björkman, I. and M. Forsgren (1997): 'Nordic Contributions to International Business Research,' in: Björkman, I. and M. Forsgren (eds.): TheNature of theIntemational Firm, Copenhagen Business School Press, Copenhagen.

Buckley, P.J and P.N. G hauri (eds.)(1999): TheIntemationalization of theFimm International Thomson Business Press, London.

Brickley, J.A. and F.H. D ark, (1987): 'The Choice of Organizational Form: The Case of Franchising,' Jaumal of Finandal Econamiss Vol. 18 (June), pp. 401-420.

Brooke, M.Z . (1985): SellingManagement Services Contradsin Intemational Business, London.

Calof, J.L. (1993): "The mode choice and change decision process and its impact on international performance,' Intemational Business Review, Vol. 2, pp. 97-120.

Cavusgil, S.T., A. Yaprak and P. L. Yeoh (1993): 'A D ecision-Making Framework for G lobal Sourcing,' Intemational Business Review, Vol. 2, No. 2, pp. 143-156.

Clark, T., D.S. Pugh and G. Mallory (1997): "The Process of Internationalization in the O perating Firm', Intemational Business Review, Vol. 6, No. 6, pp. 605-623.

Contractor, F.J. (1981): 'The role of licensing in international strategy,' Codombia Joumal of Wodd Business Vol. 16, No. 4 (Winter).

Dutta, S., M. Bergen, J.B. Heide, and G. John (1995): 'Understanding Dual Distribution: The Case of Reps and House Accounts,' Jaumal of Law Econamics, \& Organization Vol. 11, No. 1, pp. 189-204. 
Giunipero, L.C. and R.M. Monczka (1990): 'Organizational Approaches to Managing International Sourcing', Intemational Jaumal of Physical Distribution and Logistics Management, 20, pp. 3-12.

Hill, C.W.L. (1997): Intemational Business Competing in the Gldbal Markedplace (Second edition), Irwin, Burr Ridge, Illinois, USA.

Hill, C.W.L., P. Hwang, and W. C. Kim (1990): 'An eclectic theory of the choice of international entry mode,' StrategicManagenentJarmal, Vol. 11, pp. 117-128.

Johanson, J. and F. Wiedersheim-Paul (1975): "The internationalization of the firm: Four Swedish cases,' Jamal of Management Studies Vol. 12, No. 3, pp. 305-322.

Johanson, J. and J. -E. Vahlne (1977): "The internationalization process of the firm: A model of knowledge development and increasing foreign market commitment,' Jaumal of Intemational Business Studies, Vol. 8 (Third Q uarter), pp. 23-32.

Johanson, J. and J.-E. Vahlne (1990): 'The Mechanism of Internationalisation,' Intemational MarkeingReview Vol. 7, No. 4, pp. 11-24.

Korhonen, H. (1999): Invard-Outward Intemationalization of Small and Meelium Enterpises (doctoral thesis), Helsinki School of Economics and Business Administration, HeSE print, Helsinki.

Larimo, J. (1987): "The foreign direct investment process. An empirical study of the foreign direct investment decision behaviour of Finnish firms,' Procedings of the Univesity of V aasa- Resarch Paper No 124

Luostarinen, R. and L. S. Welch (1990): Intemational Business Operations Export Consulting KY, Helsinki.

Luostarinen, R., H. Korhonen, J. Jokinen, and T. Pelkonen (1994): Gldbalisation andSME. Ministry of Trade and Industry - Finland, Helsinki.

Monczka, R.M. and R. J. Trent (1991): 'Global Sourcing: A Development Approach', Intemational Jarmal of Purchasingand Materials Management, Vol. 27, No. 2, pp. 2-8.

Moxon, R.W. (1982): 'Offshore Sourcing, Subcontracting, and Manufacturing' in Walter, I. (ed.): Handbook of Intemational Business John Wiley and Sons, New Y ork.

Pedersen, T. and B. Petersen (1998): 'Explaining gradually increasing resource commitment to a foreign market', Intemational Business Review Vol. 7, pp. 483501.

Petersen, B. and T. Pedersen (1997) 'Twenty years after - support and critique of the Uppsala internationalization model.' In Björkman, I. and M. Forsgren (eds.): The Nature of theIntemational Firm Copenhagen Business School Press, Co penhagen, pp.117-134. 
Petersen, B. and L. S. Welch (1999): 'International Retailing Operations: D ownstream Entry and Expansion via Franchising,' Intemational Business Review (Forthcoming).

Schroath, F. W., M.Y. Hu and H.Y. Chen (1993): 'Country-of-O rigin Effects of Foreign Investments in the People's Republic of China,' Jamal of Intemational Business Studies Vol. 24 (Second Quarter), pp. 278-290.

Sharma, D . (1983): 'Management Contract and Internationalization,' in: Engwall, L. and J. Johanson (eds.): Some Aspets of Contrd in Intemational Business Almqvist \& Wiksell, Stockholm.

Tomassen, S., L. S. Welch, and G R.G. Benito (1998): 'Norwegian Companies in India: O peration Mode Choice,' Asian Jarmal of Business and Information Systems, Vol. 3, No. 1.

Valla, J.P. (1986): 'The French Approach to Europe', in Turnbull, P.W. and J.P. Valla (eds.): Strateges for Intemational Industrial Markeing Croom Helm, London, pp. 11-41.

Welch, L. S. (1985): 'The International Marketing of Technology: An Interaction Perspective,' Intemational MarkeingReiew Vol. 2, No. 1, pp. 41-53.

Welch, L. S. and R. Luostarinen (1993): 'Inward-Outward Connections in Internationalization,' Jaumal of Intemational Markeing Vol. 1, No. 1, pp. $44-56$.

Welch, L. S. and A. Pacifico (1990): 'Management Contracts: a role in internationalization?' Intemational MarkeingReview Vol. 7, No. 4, pp. 64-74.

Welch, L. S. (1990): 'Internationalization by Australian franchisers,' Asia PadificJamal of Management, Vol. 7, No. 2, pp. 101-121.

Williamson, P.J. (1992): 'Europe's Single Market: The Toughest Test Yet for Sales and Distribution', The Economist Intelligenee Unit: Multinational Business(summer), pp. 57-76.

Young, S. and N. Hood (1976): 'Perspectives on the European Marketing Strategy of US Multinationals', European Jaumal of Markeing Vol. 10, No. 5, pp. 240-256. 
Table 1 Types of multiple modes

Function of the local intermediary

\section{Number of observations}

Unreatedmiltiplemodes:

- Production of specific product line(s)/ licensing:

- Marketing responsibility for specific product lines:

1

1

Segmented miltiplemodes:

- Marketing responsibility for specific geographical segments:

4

- Marketing responsibility for a specific customer segment:

2

Complementarymultiplemodes

- Responsibility for special marketing functions:

Competingmiltiplemodes:

0

Fundions not speeified

8

Total: 